\title{
Contribution of the BRAF oncogene in the pre-operative phase of thyroid carcinoma
}

\author{
HOMERO GUSTAVO CORREIA RODRIGUES ${ }^{1}$, \\ ALANA ABRANTES NOGUEIRA DE PONTES ${ }^{1}$ and LUIS FERNANDO ADAN ${ }^{2}$ \\ ${ }^{1}$ School of Medicine, Federal University of Campina Grande, Campina Grande 58.429-140; \\ ${ }^{2}$ School of Medicine, Federal University of Bahia, Salvador, Bahia 40025-101, Brazil
}

Received April 5, 2012; Accepted April 24, 2013

DOI: $10.3892 / 01.2013 .1359$

\begin{abstract}
Numerous experiments have been conducted over the last few years aiming to identify molecular markers that show the diagnostic accuracy of fine-needle aspiration (FNA), particularly in thyroid lesions that are considered indeterminate. Using certain search arguments and previously defined criteria, 37 studies reporting experiments with the BRAF mutation in pre-operative FNA of the thyroid were selected from the electronic databases PUBMED, MEDLINE, SCOPUS and LILACS, in order to gather evidence with regard to the possible contribution of BRAF in the management of thyroid carcinoma. There were no cases positive for BRAF in follicular carcinomas (FTCs), Hürthle cell carcinomas (HCCs) or medullary thyroid carcinomas (MTCs). Among the 11 cases of anaplastic thyroid carcinomas (ATC), three showed positive results for the BRAF mutation. The number of cases positive for BRAF among the benign lesions was not significant. The average prevalence of BRAF-positive cases in papillary carcinomas (PTC) was $58.6 \%$, while in follicular variants of papillary carcinoma (FVPTC), the average prevalence was $29.6 \%$. For lesions diagnosed as indeterminate or suspicious, the average prevalence of BRAF positivity in PTC was $48.5 \%$. The experiments included in the present study indicated a specificity of almost $100 \%$ and a high predominance of the BRAF mutation in PTC, distinguishing the marker in the planning and medical management of papillary carcinoma of the thyroid.
\end{abstract}

\section{Introduction}

Malignant thyroid alterations are characterized by clinical and pathological variations. They are the most frequent malignant alterations of the endocrine system and the number of cases has

Correspondence to: Professor Homero Gustavo Correia Rodrigues, School of Medicine, Federal University of Campina Grande, 882 Av. Aprígio Veloso, Campina Grande 58.429-140, Brazil

E-mail: homero@huac.ufcg.edu.br

Key words: fine-needle aspiration, BRAF mutation, papillary thyroid carcinoma progressively increased over the last few years (1). The annual incidence of thyroid nodules clinically detected in adults is estimated at $0.1 \%$, with a prevalence of $4-7 \%$ in investigations using palpation, $30-50 \%$ in series that use ultrasound and $50 \%$ in autopsies $(2,3)$. Fine-needle aspiration (FNA) represents the main pre-operative tool for diagnosing thyroid nodules, due to its technical simplicity and low cost and a reported sensitivity and specificity of 70-98 and 55-100\%, respectively (4). However, certain limitations to FNA exist, due to the fact that the material obtained may not be adequate or sufficient, as its volume and quality depend on the technical executor and/or characteristics of the nodule. FNA may also be indeterminate in light of the architectural pattern and the cytological characteristics of the lesion, which may cause misunderstandings, doubts or disagreement, as the diagnosis depends on an interpretation that is frequently based on subtle and subjective criteria (5). Indeterminate situations that do not define whether the lesion is malignant represent $10-20 \%$ of the cytopathological diagnoses in material obtained from pre-operative FNA of the thyroid. Often, such limitations mean that patients must undergo surgery and all the inherent risks, not as a therapeutic act, but as a diagnostic method. Consequently, the majority of patients undergo surgery and, during the histopathological exam of the excised piece, more than two-thirds of the nodules are classified as benign, indicating that surgery was unnecessary. This creates high hospital costs and causes eventual morbidities associated with radical surgery of the thyroid $(6,7)$. Several studies have reported that tests for the identification of common somatic genetic alterations in thyroid cancer may be useful for diagnostic clarification in samples obtained from indeterminate or suspicious FNA. The RAF protein, via the BRAF isoform, has been one of the most investigated mutations for the diagnosis of nodular thyroid lesions, in isolation or combined with other oncogenes (RAS and RET/PTC) in cytological material, and has presented encouraging results (8). The most frequent mutation observed in BRAF involves the translocation of thymine for adenine at position T1799A in exon 15, which causes the substitution of the amino acid valine for glutamic acid at position V600E of the protein. The change in the amino acid activates the protein, as it allows constitutive phosphorylation of the adjacent amino acids, conferring oncogenic capacity $(9,10)$. The objective of the present study was to gather the experiments and results obtained in studies of this 
oncogene as a way to combine and analyze the contribution of BRAF in pre-operative FNA of the thyroid.

\section{Materials and methods}

A broad review of the literature was conducted using the principles of systematic review. The search strategy included using the electronic bibliographical databases PUBMED, MEDLINE, SCOPUS and LILACS between January 2004 and June 2011. The keywords 'thyroid' and 'fine-needle aspiration' were combined with 'BRAF' and 'molecular marker'. The inclusion criteria were defined as follows: i) The article should have been written in English, French, Italian, Spanish or Portuguese; ii) the main or secondary objective of the study must have been to evaluate the expression of the proto-oncogene BRAF, in isolation or as part of a panel, in material from FNA; iii) the marker should have been submitted for evaluation in samples obtained at the pre-operative phase; and iv) the histopathology of the piece from the surgical resection must have been considered the gold standard of diagnosis. Using these predefined criteria, two of the authors examined the articles that were recovered. The information extracted from the studies included the year of publication, the name of the periodical, the country where the research group was based, the approval register of the experiment conferred by an ethics committee, the distribution of the sample according to gender and age, the number and histological types of the malignant lesions studied in the investigation, the method of analysis of the BRAF gene, the number of cytopathologists involved in the experiment and the identification of other markers when the study involved experiments in panels.

\section{Results}

The 37 experiments included in the present study were published in 21 different periodicals and were conducted by research groups in eight countries; there were 12 studies in the United States, 10 in Korea, nine in Italy, two in China, one in Germany, one in Japan, one in France and one in Portugal. All of the studies were written in English, with the exception of one that was published in French. The majority of the studies (72.9\%) made reference to the approval of the experiment by an ethics committee or equivalent research body that the institution the group belonged to. No gender differentiation was made with regard to the participants in $51.3 \%$ of the studies. The other participants were identified as 1,209 females and 446 males. The age of the participants was not mentioned in $45.9 \%$ of the studies. Among the studies that indicated the age, it was possible to observe that the average age was 46.1 years.

In total, the experiments involved 3,029 thyroid malignant lesions, these included 2,732 papillary carcinomas of the thyroid (PTC), 183 follicular variants of papillary carcinoma (FVPTC), 79 follicular carcinomas (FTC), 19 medullary carcinomas (MTC), 11 anaplastic carcinomas (ATC) and five Hürthle cell carcinomas (HCC; Table I). Polymerase chain reaction (PCR) direct sequencing was the predominantly employed method for analyzing the presence of the BRAF gene in the samples. Several studies (67.5\%) did not register the number of cytopathologists involved in the process or analysis of the results. In ten studies, the BRAF gene was submitted for analysis in a panel with other markers, particularly the oncogene RET/PTC (Table II). The majority of the studies (75.6\%) included samples of indeterminate or suspicious FNA, with 1,366 lesions studied altogether (Table III).

There were no BRAF-positive cases in the FTCs, HCCs or MTCs. Among the 11 ATC cases, three were positive for the BRAF mutation. The number of cases positive for BRAF among the benign lesions was not significant. The average prevalence of BRAF-positive cases of PTC was 58.6\%, while in FVPTC, the average prevalence was $29.6 \%$. For lesions with indeterminate or suspicious diagnoses, the average prevalence of BRAF-positive cases of PTC was $48.5 \%$.

\section{Discussion}

Thyroid nodules are a common condition, but occasionally represent a challenge in the differentiation of benign and malignant lesions. FNA presents with excellent diagnostic precision in the majority of cases; however, a significant percentage of FNA samples are indeterminate, justifying the efforts of several research groups in identifying molecular markers to improve the diagnostic accuracy of FNA of the thyroid. FNAs that indicate thyroid cancer are rarely false-positive (8). In this case, it is possible to conclude that a biomolecular study of the lesion would have little or no importance. However, even such situations justify new approaches, as cytomorphological study of the lesion is not sufficient for the risk stratification and/or proper establishment of medical management measures of the lesion. In this regard, the BRAF mutation has received special attention in the last few years.

Among the four types of thyroid carcinoma, PTC is the most prevalent, responsible for $80-90 \%$ of all malignant neoplasms of the thyroid $(10,11)$ and its incidence has been growing rapidly in several areas of the world (12). The samples of the experiments included in the present study revealed an average prevalence of PTC in the order of $96 \%$ $[(2,732+183) / 3,029 \times 100]$. It is in this type of lesion that there is a more frequent occurrence of the BRAF mutation. It has been reported that the mutation is present in between 28.8 and $69 \%$ of PTCs (13). In the present series, an average prevalence of $58.6 \pm 20.8 \%$ (range, $15-91 \%$ ) was obtained. PTC is frequently associated with an excellent prognosis and low mortality, but not all patients share such a result (14). This is mainly due to inaccurate information concerning the aggressiveness and level of the tumor in the pre-operative phase (11).

Several studies $(11,15-17)$ have identified the existence of controversy with regard to surgical planning for patients whose cytological aspirations were malignant or indeterminate, and with regard to whether they should undergo partial or total thyroidectomy. In certain cases of lobectomy, the excised nodule is malignant in the histopathological exam, which inevitably requires a second surgery to complete the thyroidectomy, generating additional costs and increasing the possibility of complications and morbidity.

The analysis of the presence of the BRAF mutation in the material obtained from pre-operative FNA is a useful strategy for the reduction of such imprecision and controversies. The specificity with this analysis has been reported at $100 \%$ (18), i.e. BRAF mutations are not identified in benign lesions, 
Table I. Studies, analysis method, number of malignant lesions and results of BRAF detection in FNA pre-operative.

\begin{tabular}{|c|c|c|c|c|c|c|c|c|}
\hline \multirow[b]{2}{*}{ First author (ref.) } & \multirow[b]{2}{*}{ Year } & \multirow[b]{2}{*}{ Analysis method } & \multicolumn{6}{|c|}{ Number of malignant lesions / $\mathrm{BRAF}^{+}$} \\
\hline & & & PTC & FVPTC & FTC & $\mathrm{HCC}$ & ATC & MTC \\
\hline Salvatore et al (17) & 2004 & PCR - direct sequencing/SSCP & $47 / 23$ & $22 / 3$ & & & & \\
\hline Cohen et al (22) & 2004 & $\begin{array}{l}\text { PCR direct sequencing and } \\
\text { Mutector assay }\end{array}$ & $27 / 18$ & $27 / 4$ & $2 / 0$ & $1 / 0$ & $1 / 1$ & $1 / 0$ \\
\hline Hayashida et al (13) & 2004 & PCR - RFLP & $21 / 5$ & & & & & \\
\hline Xing et al (23) & 2004 & $\begin{array}{l}\text { PCR - colorimetric mutation } \\
\text { detection method }\end{array}$ & $16 / 7$ & & $5 / 0$ & $1 / 0$ & & \\
\hline Domingues et al (24) & 2005 & PCR - Direct sequencing & $11 / 3$ & & $1 / 0$ & & & $1 / 0$ \\
\hline Chung et al (25) & 2006 & PCR - Direct sequencing & $107 / 92$ & & $3 / 0$ & & $2 / 1$ & \\
\hline Jin et al (26) & 2006 & $\begin{array}{l}\text { PCR - Direct sequencing, } \\
\text { colorimetric Mutector assay, } \\
\text { LightCycler PCR and } \\
\text { allele-specific PCR }\end{array}$ & $45 / 29$ & $13 / 2$ & & & & \\
\hline Rowe et al (16) & 2006 & LightCycler PCR & $19 / 3$ & & & & & \\
\hline Pizzolanti et al (27) & 2007 & Real-time allele-specific-PCR & $14 / 10$ & $2 / 1$ & $1 / 0$ & & & \\
\hline Sapio et al (28) & 2007 & PCR-MASA & $6 / 4$ & & $1 / 0$ & & & $1 / 0$ \\
\hline Sapio et al (18) & 2007 & PCR-MASA & $21 / 10$ & & $5 / 0$ & & & \\
\hline Kim et al (29) & 2008 & PCR-Pyrosequencing & $73 / 63$ & $2 / 0$ & $3 / 0$ & & $1 / 0$ & $1 / 0$ \\
\hline Zatelli et al (4) & 2009 & PCR-Direct sequencing/RFLP & $58 / 41$ & $16 / 6$ & $7 / 0$ & & $1 / 1$ & $6 / 0$ \\
\hline Nikiforov et al (15) & 2009 & LightCycler PCR/FMCA & $38 / 18$ & & $6 / 0$ & & $2 / 0$ & $2 / 0$ \\
\hline Moon et al (30) & 2009 & PCR - Direct sequencing & $84 / 42$ & & & & & \\
\hline Marchetti et al (31) & 2009 & PCR - Direct sequencing & $89 / 59$ & & & & $2 / 0$ & \\
\hline Bentz et al (32) & 2009 & LightCycler PCR/FMCA & $24 / 18$ & $16 / 6$ & & & & \\
\hline Kwak et al (21) & 2009 & PCR - Direct sequencing & $339 / 213$ & & & & & \\
\hline Xing et al (11) & 2009 & $\begin{array}{l}\text { PCR - Colorimetric mutation } \\
\text { detection method }\end{array}$ & $149 / 68$ & $41 / 5$ & & & & \\
\hline Yip et al (14) & 2009 & PCR-FMCA & $44 / 31$ & & & & & \\
\hline Kim et al (33) & 2009 & PCR - Pyrosequencing & $101 / 88$ & & & & & \\
\hline Jo et al (34) & 2009 & PCR - Pyrosequencing & $40 / 30$ & & & & & \\
\hline Hwang et al (12) & 2010 & $\begin{array}{l}\text { PCR - Direct sequencing and } \\
\text { allele-specific PCR }\end{array}$ & $135 / 106$ & & & & & \\
\hline Lin et al (35) & 2010 & PCR - Direct sequencing & $61 / 21$ & & & & & \\
\hline Dujardin et al (36) & 2010 & PCR - Direct sequencing & $10 / 7$ & & & & & \\
\hline Girlando et al (37) & 2010 & PCR - Direct sequencing & $44 / 34$ & $16 / 9$ & & & & \\
\hline Musholt et al (38) & 2010 & PCR - MASA & $22 / 9$ & & $4 / 0$ & & $1 / 0$ & $1 / 0$ \\
\hline Kim et al (39) & 2010 & DPO-based multiplex PCR & $263 / 221$ & & $4 / 0$ & & & $1 / 0$ \\
\hline Guo et al (40) & 2010 & PCR - Direct sequencing & $8 / 4$ & & & & & \\
\hline Kwak et al (41) & 2010 & DPO-Based Multiplex PCR & $107 / 86$ & $2 / 1$ & & & & \\
\hline Ohori et al (42) & 2010 & LightCycler PCR & $20 / 3$ & & & & & \\
\hline Moses et al (43) & 2010 & PCR - Direct sequencing & $70 / 20$ & $19 / 3$ & $8 / 0$ & $2 / 0$ & $1 / 0$ & $1 / 0$ \\
\hline Cantara et al (8) & 2010 & PCR - Direct sequencing & $74 / 33$ & & $3 / 0$ & $1 / 0$ & & \\
\hline Kim et al (44) & 2011 & PCR-Pyrosequencing & $169 / 154$ & & $4 / 0$ & & & \\
\hline Yeo et al (45) & 2011 & PCR- Pyrosequencing & $175 / 95$ & $7 / 4$ & $6 / 0$ & & & $4 / 0$ \\
\hline Adeniran et al (46) & 2011 & PCR - Direct sequencing/SSCP & $60 / 40$ & & & & & \\
\hline Pelizzo et al (47) & 2011 & PCR - Direct sequencing/MASA & $141 / 98$ & & $16 / 0$ & & & \\
\hline
\end{tabular}

FNA, fine-needle aspiration; PTC, papillary thyroid carcinoma; FVPTC, follicular variant of papillary thyroid carcinoma; FTC, follicular thyroid carcinoma; HCC, Hürthle cell carcinoma; ATC, anaplastic thyroid carcinoma; MTC, medullary thyroid carcinoma; PCR, polymerase chain reaction; MASA, mutant allele-specific amplification; DPO, dual-priming oligonucleotide; RFLP, restriction fragment length polymorphism; SSCP, single-strand conformational polymorphism; FMCA, fluorescence melting curve analysis. 
Table II. Distribution of studies according to the types and quantity of markers used in panel with the BRAF gene.

\begin{tabular}{|c|c|c|}
\hline First author (ref.) & Year & Markers used \\
\hline Cantara et al (8) & 2010 & BRAF, RET, RAS, TRK ${ }^{\mathrm{a}}, \mathrm{PAX}^{\mathrm{a}}$ \\
\hline Salvatore et al (17) & 2004 & BRAF, RET \\
\hline Moses et al (43) & 2010 & BRAF, RET, RAS \\
\hline Nikiforov et al (15) & 2009 & BRAF, RET, RAS, PAX8 ${ }^{\mathrm{b}}$ \\
\hline Musholt et al (38) & 2010 & BRAF, RET \\
\hline Sapio et al (18) & 2007 & GAL-3, BRAF \\
\hline Sapio et al (28) & 2007 & BRAF, RET, TRK ${ }^{\mathrm{a}}$ \\
\hline Pizzolanti et al (27) & 2007 & BRAF, RET \\
\hline Domingues et al (24) & 2004 & BRAF, RET \\
\hline Ohori et al (42) & 2010 & BRAF, RET, RAS, PAX8 ${ }^{\mathrm{b}}$ \\
\hline
\end{tabular}

${ }^{a}$ No mutation in the samples selected. ${ }^{b}$ Only one mutation present in the sample.

Table III. Distribution of studies according to number of thyroid papillary carcinomas in the indeterminate or suspicious cytological samples and the number positive for BRAF mutation.

\begin{tabular}{|c|c|c|c|}
\hline First author (ref.) & Total of FNAs & $\begin{array}{l}\text { Indeterminate or suspicious } \\
\text { lesions / PTC number }\end{array}$ & $\begin{array}{c}\text { Indeterminate or suspicious } \\
\text { lesions / } \mathrm{BRAF}^{+}\end{array}$ \\
\hline Moses et al (43) & 196 & 137/33 (19 FVPTC) & 137/13 (3FVPTC) \\
\hline Cantara et al (8) & 235 & $95 / 53$ & $95 / 23$ \\
\hline Nikiforov et al (15) & 86 & $52 / 17$ & $52 / 7$ \\
\hline Sapio et al (18) & 144 & $94 / 2$ & $94 / 10$ \\
\hline Rowe et al (16) & 24 & $19 / 19$ & $19 / 3$ \\
\hline Salvatore et al (17) & 96 & 34/15 (6 FVPTC) & 34/4 (1 FVPTC) \\
\hline Xing et al (11) & 45 & $25 / 7$ & $25 / 2$ \\
\hline Cohen et al (22) & 91 & 55/29 (21 FVPTC) & 55/5 (2 FVPTC) \\
\hline Musholt et al (38) & 93 & $19 / 4$ & $19 / 1$ \\
\hline Dujardin et al (36) & 25 & $13 / 7$ & $13 / 4$ \\
\hline Kim et al (39) & 279 & $80 / 70$ & $80 / 50$ \\
\hline Kwak et al (41) & 130 & $30 / 20$ & $30 / 16$ \\
\hline Ohori et al (42) & 117 & $117 / 20$ & $117 / 3$ \\
\hline Moon et al (30) & 91 & $91 / 84$ & $91 / 42$ \\
\hline Marchetti et al (31) & 111 & $52 / 33$ & $33 / 18$ \\
\hline Bentz et al (33) & 45 & $17 / 17$ & $17 / 3$ \\
\hline Jo et al (34) & 101 & $24 / 9$ & $24 / 7$ \\
\hline Pizzolanti et al (27) & 156 & 19/3 (1 FVPTC) & 19/2 (1FVPTC) \\
\hline Sapio et al (28) & 132 & $37 / 6$ & $37 / 4$ \\
\hline Chung et al (25) & 137 & $25 / 5$ & $25 / 3$ \\
\hline Domingues et al (24) & 24 & $10 / 1$ & $10 / 0$ \\
\hline Hayashida et al (13) & 21 & $1 / 1$ & $1 / 1$ \\
\hline Yeo et al (45) & 209 & 63/49 (5 FVPTC) & 63/14 (3 FVPTC) \\
\hline Adeniran et al (46) & 72 & $34 / 22$ & $34 / 10$ \\
\hline Pelizzo et al (47) & 270 & $164 / 45$ & $164 / 30$ \\
\hline Jin et al (26) & 71 & $12 /\left({ }^{\mathrm{a}}\right)$ & $12 / 1$ \\
\hline Girlando et al (37) & 91 & $20 / 14$ & $20 / 10$ \\
\hline Kim et al (29) & 103 & 27/18 (2 FVPTC) & $27 / 13$ \\
\hline
\end{tabular}

${ }^{a}$ Not determined. FNA, fine-needle aspiration; PTC, papillary thyroid carcinoma; FVPTC, follicular variant of papillary thyroid carcinoma. 
instead being present only in malignant lesions, particularly PTCs. The presence of the BRAF mutation does not identify malignant lesions totally (low sensibility), although its presence does offer the certainty of the result being a true positive. Moreover, it has been suggested that individuals whose nodules exhibit the BRAF mutation are patients who are more likely to be submitted for total thyroidectomy surgery, independently from the cytological results (4). In addition, in PTC, the BRAF mutation is intimately associated with extra-thyroidean extension, lymph node metastasis and advanced tumor stages $(19,20)$, which are the main clinicopathological risk factors conventionally associated with the increase of recurrence and mortality rates for thyroid cancer (21). Although there are controversies $(13,46,47)$, the conclusions of a meta-analytical study by Lee et al (20) revealed the absence of any correlation between the marker and the patients' ethnicity, age, gender or tumor size. With such qualifications, the detection of the BRAF mutation in pre-operative FNA makes it possible to speed up patient management, while avoiding other less specific diagnostic tests, such as FNA repetition, scintigraphy or freezing intraoperative assessment (22), as well as the decision concerning the extension of surgical resection to prevent the performance of a second surgery (18).

However, it is clear that the frequency of the BRAF mutation does not occur in a uniform manner among the PTC variants. BRAF mutations are more frequent in the high cell variant, followed by the conventional type and then the follicular variant (20). In the specific case of FVPTC in the present study, the average prevalence of the BRAF mutation was $29.6 \%$. This PTC variant deserves special attention as the cytological diagnosis may be difficult due to the superimposition of morphological characteristics with benign or non-neoplastic lesions (17). The presence of positivity for the BRAF mutation is not a predictive factor of a worst prognosis in FVPTC as it is largely considered in the other PTC variants (22).

A number of the experiments on the BRAF mutation included in the present study were performed in panel form, mainly with other oncogenes (RAS and RET/PTC). The objective of these experiements was to increase the pre-operative FNA diagnostic sensibility, as the BRAF mutation does not occur together with the RAS mutation or the RET-PTC rearrangement, indicating different genetic alterations in the pathogenesis of the papillary carcinoma (9).

In conclusion, considering the association between the BRAF mutation and tumor extension and aggressiveness, we recommend that the establishment of a BRAF mutation detection routine should be analyzed in order to apply this approach in morphologically suspicious or indeterminate FNA, and for pre-operative planning for thyroid cancer.

\section{References}

1. Pilli T, Prasad KV, Jayarama S, Pacini F and Prabhakar BS: Potential utility and limitations of thyroid cancer cell lines as models for studying thyroid cancer. Thyroid 19: 1333-1342, 2009.

2. Alves MLD, Maciel RMB, Valeri FV, Silva MRDD, Contrera JD, Andrade JM, Llorach-Velludo MA and Iazigi N: Prediction of malignancy in the solitary thyroid nodule by physical examination, thyroid scintigraphy, thyroid ultrasound, fine-needle biopsy and serum thyroglobulin: a prospective study of 110 operated patients. Arq Bras Endocrinol Metabol 46: 648-653, 2002 (In Portuguese).
3. Cerutti JM: Nodule diagnosed as follicullar patterned lesion: are biomarkers the promise? Arq Bras Endocrinol Metabol 51: 832-842, 2007.

4. Zatelli MC, Trasforini G, Leoni S, Frigato G, Buratto M, Tagliati F, Rossi R, Cavazzini L, Roti E and degli Uberti EC: BRAF V600E mutation analysis increases diagnostic accuracy for papillary thyroid carcinoma in fine-needle aspiration biopsies. Eur J Endocrinol 161: 467-473, 2009.

5. Suster S: Thyroid tumors with a follicular growth pattern: problems in differential diagnosis. Arch Pathol Lab Med 130: 984-988, 2006.

6. Segura MEA and Magalhães AV: Galectin-3 immunostaining in thyroid neoplasms. J Bras Patol Med Lab 41: 341-346, 2005.

7. Rosa MP: Expression of galectin-3 and cytokeratin 19 in the epithelial neoplasm of the thyroid gland and histopathological correlation. Jornal brasileiro de patologia e medicina laboratorial 41: 61-70, 2005.

8. Cantara S, Capezzone M, Marchisotta S, Capuano S, Busonero G, Toti P, Di Santo A, Caruso G, Carli AF, Brilli L, Montanaro A and Pacini F: Impact of proto-oncogene mutation detection in cytological specimens from thyroid nodules improves the diagnostic accuracy of cytology. J Clin Endocrinol Metab 95: 1365-1369, 2010.

9. Kimura ET, Nikiforova MN, Zhu Z, Knauf JA, Nikiforov YE and Fagin JA: High prevalence of BRAF mutations in thyroid cancer: genetic evidence for constitutive activation of the RET/PTC-RAS-BRAF signaling pathway in papillary thyroid carcinoma. Cancer Res 63: 1454-1457, 2003.

10. Li Y, Nakamura M and Kakudo K: Targeting of the BRAF gene in papillary thyroid carcinoma (review). Oncol Rep 22: 671-681, 2009.

11. Xing M, Clark D, Guan H, Ji M, Dackiw A, Carson KA, Kim M, Tufaro A, Ladenson P, Zeiger M and Tufano R: BRAF mutation testing of thyroid fine-needle aspiration biopsy specimens for pre-operative risk stratification in papillary thyroid cancer. J Clin Oncol 27: 2977-2982, 2009.

12. Hwang J, Shin JH, Han BK, Ko EY, Kang SS, Kim JW and Chung JH: Papillary thyroid carcinoma with BRAFV600E mutation: sonographic prediction. Am J Roentgenol 194: W425-W430, 2010.

13. Hayashida N, Namba H, Kumagai A, Hayashi T, Ohtsuru A, Ito M, Saenko VA, Maeda S, Kanematsu T and Yamashita S: A rapid and simple detection method for the BRAF(T1796A) mutation in fine-needle aspirated thyroid carcinoma cells. Thyroid 14: 910-915, 2004.

14. Yip L, Nikiforova MN, Carty SE, Yim JH, Stang MT, Tublin MJ, Lebeau SO, Hodak SP, Ogilvie JB and Nikiforov YE: Optimizing surgical treatment of papillary thyroid carcinoma associated with BRAF mutation. Surgery 146: 1215-1223, 2009.

15. Nikiforov YE, Steward DL, Robinson-Smith TM, Haugen BR, Klopper JP, Zhu Z, Fagin JA, Falciglia M, Weber K and Nikiforova MN: Molecular testing for mutations in improving the fine-needle aspiration diagnosis of thyroid nodules. J Clin Endocrinol Metab 94: 2092-2098, 2009.

16. Rowe LR, Bentz BG and Bentz JS: Utility of BRAF V600E mutation detection in cytologically indeterminate thyroid nodules. Cytojournal 3: 10, 2006

17. Salvatore G, Giannini R, Faviana P, Caleo A, Migliaccio I, Fagin JA, Nikiforov YE, Troncone G, Palombini L, Basolo F and Santoro M: Analysis of BRAF point mutation and RET/PTC rearrangement refines the fine-needle aspiration diagnosis of papillary thyroid carcinoma. J Clin Endocrinol Metab 89: 5175-5180, 2004.

18. Sapio MR, Guerra A, Posca D, Limone PP, Deandrea M, Motta M, Troncone G, Caleo A, Vallefuoco P, Rossi G, Fenzi G and Vitale M: Combined analysis of galectin-3 and BRAFV600E improves the accuracy of fine-needle aspiration biopsy with cytological findings suspicious for papillary thyroid carcinoma. Endocr Relat Cancer 14: 1089-1097, 2007.

19. Xing M: Prognostic utility of BRAF mutation in papillary thyroid cancer. Mol Cell Endocrinol 321: 86-93, 2010.

20. Lee JH, Lee ES and Kim YS: Clinicopathologic significance of BRAF V600E mutation in papillary carcinomas of the thyroid: a meta-analysis. Cancer 110: 38-46, 2007.

21. Kwak JY, Kim EK, Chung WY, Moon HJ, Kim MJ and Choi JR: Association of BRAFV600E mutation with poor clinical prognostic factors and US features in Korean patients with papillary thyroid microcarcinoma. Radiology 253: 854-860, 2009.

22. Cohen Y, Rosenbaum E, Clark DP, Zeiger MA, Umbricht CB, Tufano RP, Sidransky D and Westra WH: Mutational analysis of BRAF in fine needle aspiration biopsies of the thyroid: A potential application for the pre-operative assessment of thyroid nodules. Clin Cancer Res 10: 2761-2765, 2004. 
23. Xing MZ, Tufano RP, Tufaro AP, Basaria S, Ewertz M, Rosenbaum E, Byrne PJ, Wang J, Sidransky D and Ladenson PW: Detection of BRAF mutation on fine needle aspiration biopsy specimens: a new diagnostic tool for papillary thyroid cancer. J Clin Endocrinol Metab 89: 2867-2872, 2004.

24. Domingues R, Mendonça E, Sobrinho L and Bugalho MJ: Searching for RET/PTC rearrangements and BRAF V599E mutation in thyroid aspirates might contribute to establish a pre-operative diagnosis of papillary thyroid carcinoma. Cytopathology 16: 27-31, 2005.

25. Chung KW, Yang SK, Lee GK, Kim EY, Kwon S, Lee SH, Park do J, Lee HS, Cho BY, Lee ES and Kim SW: Detection of BRAFV600E mutation on fine needle aspiration specimens of thyroid nodule refines cyto-pathology diagnosis, especially in BRAFV600E mutation-prevalent area. Clinical Endocrinol (Oxf) 65: 660-666, 2006.

26. Jin L, Sebo TJ, Nakamura N, Qian X, Oliveira A, Majerus JA, Johnson MR and Lloyd RV: BRAF mutation analysis in fine needle aspiration (FNA) cytology of the thyroid. Diagn Mol Pathol 15: 136-143, 2006.

27. Pizzolanti G, Russo L, Richiusa P, Bronte V, Nuara RB, Rodolico V, Amato MC, Smeraldi L, Sisto PS, Nucera M, Bommarito A, Citarrella R, Lo Coco R, Cabibi D, Lo Coco A Frasca F, Gulotta G, Latteri MA, Modica G, Galluzzo A and Giordano C: Fine-needle aspiration molecular analysis for the diagnosis of papillary thyroid carcinoma through BRAF V600E mutation and RET/PTC rearrangement. Thyroid 17: 1109-1115, 2007.

28. Sapio MR, Posca D, Raggioli A, Guerra A, Marotta V, Deandrea M, Motta M, Limone PP, Troncone G, Caleo A, Rossi G, Fenzi G and Vitale M: Detection of RET/PTC, TRK and BRAF mutations in pre-operative diagnosis of thyroid nodules with indeterminate cytological findings. Clin Endocrinol 66 : 678-683, 2007.

29. Kim SK, Kim DL, Han HS, Kim WS, Kim SJ, Moon WJ, Oh SY and Hwang TS: Pyrosequencing analysis for detection of a BRAFV600E mutation in an FNAB specimen of thyroid nodules. Diagn Mol Pathol 17: 118-125, 2008.

30. Moon HJ, Kwak JY, Kim EK, Choi JR, Hong SW, Kim MJ and Son EJ: The role of BRAFV600E mutation and ultrasonography for the surgical management of a thyroid nodule suspicious for papillary thyroid carcinoma on cytology. Ann Surg Oncol 16: 3125-3131, 2009.

31. Marchetti I, Lessi F, Mazzanti CM, Bertacca G, Elisei R, Coscio G, Pinchera A and Bevilacqua G: A morpho-molecular diagnosis of papillary thyroid carcinoma: BRAF V600E detection as an important tool in pre-operative evaluation of fine-needle aspirates. Thyroid 19: 837-842, 2009.

32. Bentz BG, Miller BT, Holden JA, Rowe LR and Bentz JS: B-RAF V600E mutational analysis of fine needle aspirates correlates with diagnosis of thyroid nodules. Otolaryngol Head Neck Surg 140: 709-714, 2009.

33. Kim SK, Song KH, Lim SD, Lim YC, Yoo YB, Kim JS and Hwang TS: Clinical and pathological features and the BRAF(V600E) mutation in patients with papillary thyroid carcinoma with and without concurrent Hashimoto thyroiditis. Thyroid 19: 137-141, 2009.

34. Jo YS, Huang S, Kim YJ, Lee IS, Kim SS, Kim JR, Oh T, Moon Y, An S, Ro HK, Kim JM and Shong M: Diagnostic value of pyrosequencing for the BRAF V600E mutation in ultrasound-guided fine-needle aspiration biopsy samples of thyroid incidentalomas. Clin Endocrinol (Oxf) 70: 139-144, 2009.
35. Lin KL, Wang OC, Zhang XH, Dai XX, Hu XQ and Qu JM: The BRAF mutation is predictive of aggressive clinicopathological characteristics in papillary thyroid microcarcinoma. Ann Surg Oncol 17: 3294-3300, 2010

36. Dujardin F, Pagès JC, Collin $C$, de Calan L, Lecomte $P$ and Guyétant S: BRAF V600E mutation in papillary thyroid carcinoma: prevalence and detection in fine needle aspiration specimens. Ann Pathol 30: 252-262, 2010 (In French).

37. Girlando S, Cuorvo LV, Bonzanini M, Morelli L, Amadori P, Dalla Palma P and Barbareschi M: High prevalence of B-RAF mutation in papillary carcinoma of the thyroid in north-east Italy. Int J Surg Pathol 18: 173-176, 2010.

38. Musholt TJ, Fottner C, Weber MM, Eichhorn W, Pohlenz J, Musholt PB, Springer E and Schad A: Detection of papillary thyroid carcinoma by analysis of BRAF and RET/PTC1 mutations in fine-needle aspiration biopsies of thyroid nodules. World J Surg 34: 2595-2603, 2010.

39. Kim SW, Lee JI, Kim JW, Ki CS, Oh YL, Choi YL, Shin JH, Kim HK, Jang HW and Chung JH: BRAFV600E mutation analysis in fine-needle aspiration cytology specimens for evaluation of thyroid nodule: a large series in a BRAFV600E-prevalent population. J Clin Endocrinol Metab 95: 3693-3700, 2010.

40. Guo F, Hou P and Shi B: Detection of BRAF mutation on fine needle aspiration biopsy specimens: diagnostic and clinical implications for papillary thyroid cancer. Acta Cytol 54: 291-295, 2010.

41. Kwak JY, Kim EK, Kim JK, Han JH, Hong SW, Park TS and Choi JR: Dual priming oligonucleotide-based multiplex PCR analysis for detection of BRAF(V600E) mutation in FNAB samples of thyroid nodules in BRAF(V600E) mutation-prevalent area. Head Neck 32: 490-498, 2010.

42. Ohori NP, Nikiforova MN, Schoedel KE, LeBeau SO, Hodak SP, Seethala RR, Carty SE, Ogilvie JB, Yip L and Nikiforov YE: Contribution of molecular testing to thyroid fine-needle aspiration cytology of 'follicular lesion of undetermined significance/atypia of undetermined significance'. Cancer Cytopathol 118: 17-23, 2010.

43. Moses W, Weng J, Sansano I, Peng M, Khanafshar E, Ljung BM, Duh QY, Clark $\mathrm{OH}$ and Kebebew E: Molecular testing for somatic mutations improves the accuracy of thyroid fine-needle aspiration biopsy. World J Surg 34: 2589-2594, 2010.

44. Kim SK, Hwang TS, Yoo YB, Han HS, Kim DL, Song KH, Lim SD, Kim WS and Paik NS: Surgical results of thyroid nodules according to a management guideline based on the BRAF(V600E) mutation status. J Clin Endocrinol Metab 96: 658-664, 2011

45. Yeo MK, Liang ZL, Oh T, Moon Y, An S, Kim MK, Kim KS, Shong M, Kim JM and Jo YS: Pyrosequencing cut-off value identifying BRAFV600E mutation in fine needle aspiration samples of thyroid nodules. Clin Endocrinol (Oxf) 75: 555-560, 2011.

46. Adeniran AJ, Theoharis C, Hui P, Prasad ML, Hammers L, Carling T, Udelsman R and Chhieng DC: Reflex BRAF testing in thyroid fine-needle aspiration biopsy with equivocal and positive interpretation: a prospective study. Thyroid 21: 717-723, 2011.

47. Pelizzo MR, Boschin IM, Barollo S, Pennelli G, Toniato A, Zambonin L, Vianello F, Piotto A, Ide EC, Pagetta C, Sorgato N, Torresan F, Girelli ME, Nacamulli D, Mantero F and Mian C: BRAF analysis by fine needle aspiration biopsy of thyroid nodules improves pre-operative identification of papillary thyroid carcinoma and represents a prognostic factor. A mono-institutional experience. Clin Chem Lab Med 49: 325-329, 2011. 